
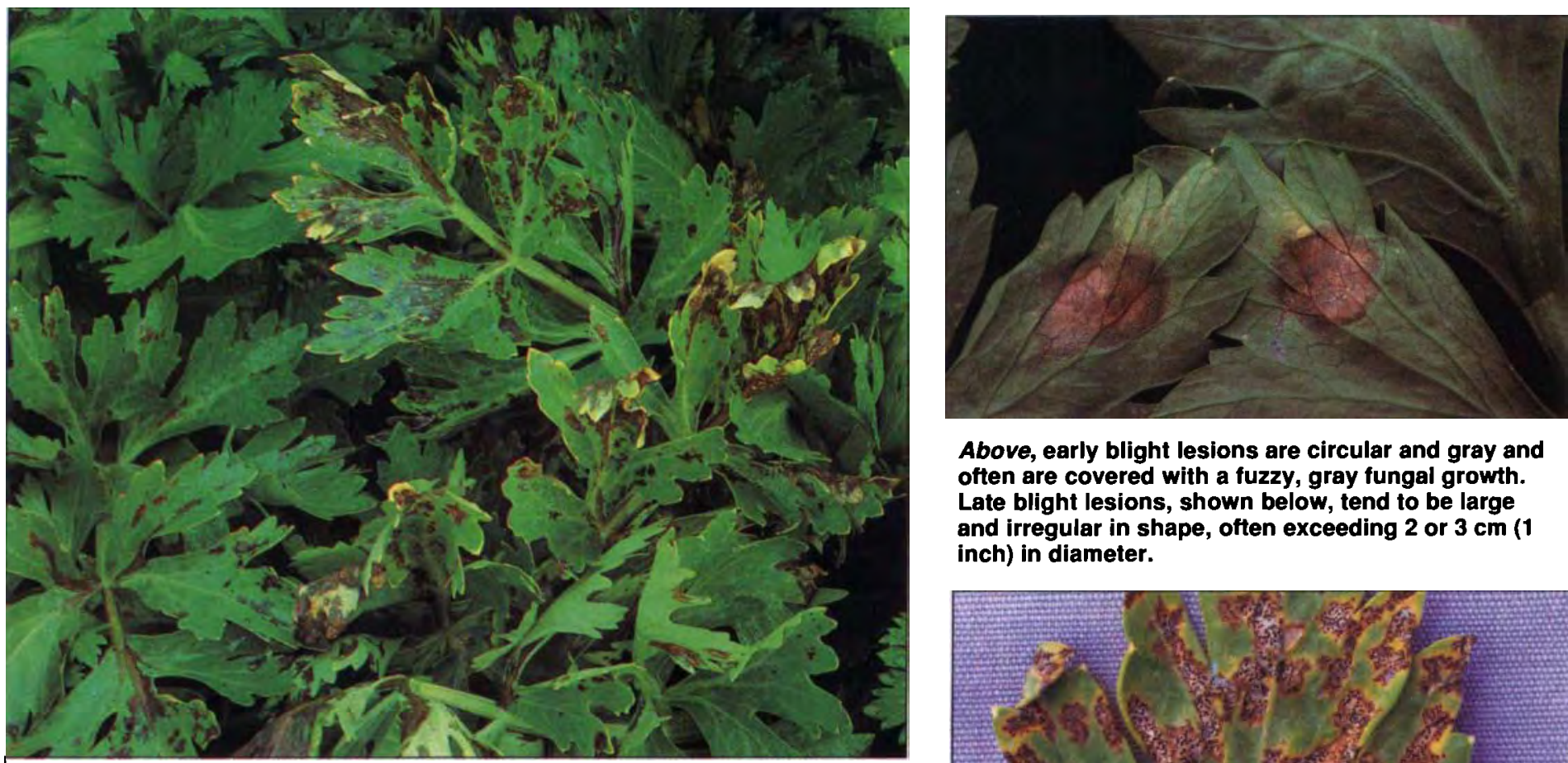

Above, early blight lesions are circular and gray and often are covered with a fuzzy, gray fungal growth. Late blight lesions, shown below, tend to be large and irregular in shape, often exceeding 2 or $3 \mathrm{~cm}(1$ inch) in diameter.

On field grown celery, bacterial blight lesions are usually found on the lower, older leaves. Severe bacterial blight symptoms, shown here, were observed in fields that had been sprinkler-irrigated through production.

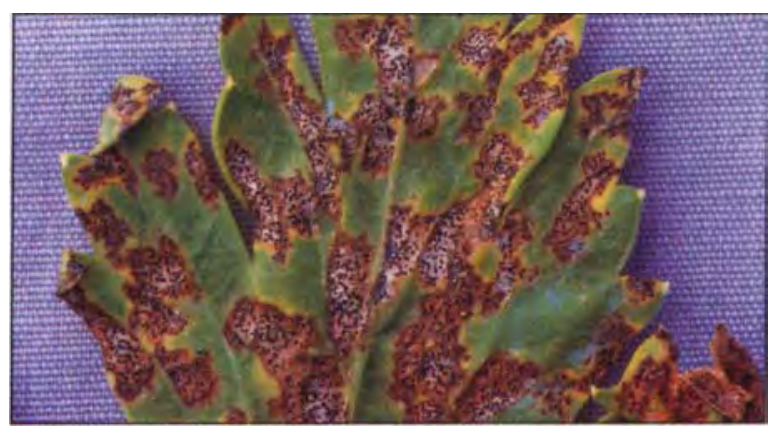

\title{
New celery disease appears in California
}

\author{
Steven T. Koike $\square \quad$ Elizabeth L. Little $\square$ Andrew L. Bishop $\square \quad$ Robert L. Gilbertson
}

\begin{abstract}
A bacterial disease of celery, caused by Pseudomonas syringae pv. apii, has been identified for the first time in California. Bacterial blight develops on greenhouse-grown transplants and has spread into production fields throughout coastal regions of the state. Although this disease can be confused with fungal celery blights caused by Septoria apiicola and Cercospora apii, it has several distinguishing characteristics.
\end{abstract}

In California, celery is almost always planted in the field as transplants, which are produced in commercial vegetable transplant greenhouses. Transplants compensate for the uneven germination of celery seed and the slow growth of celery seedlings, yielding a more uniform celery crop in the field. However, certain conditions in transplant greenhouses favor the outbreak of plant diseases on celery transplants. For example, celery late blight, caused by the seedborne fungus Septoria apiicola, can reach high levels on greenhouse-grown celery. Plants infected at this early stage become significant inoculum sources that later may cause economic losses.

In 1989, unfamiliar disease symptoms were observed on leaves of fieldgrown celery in Santa Barbara County that did not match those associated with the well-known fungal blight diseases. The following year, similar symptoms were detected on fieldgrown celery and greenhouse celery transplants in Monterey County. Because of these observations, we conducted studies to identify the cause of the disease and to determine its incidence in the field.

The initial symptoms, found both on transplants and in the field, were small - less than $1 \mathrm{~cm}$ (0.4 inches) in diameter - water-soaked spots (lesions) visible on the upper and lower leaf surfaces. As these lesions expanded, they were delimited by leaf veins, which gave them an angular appearance. In most cases, the lesions turned dark brown; however, under dry conditions they bleached out and appeared as light tan necrotic spots. Lesions sometimes coalesced to cover large areas of an infected leaf but were rarely observed on leaf petioles. No fungal fruiting structures were observed within lesions, but when examined with a light microscope, tissues from lesion margins consistently revealed large amounts of bacteria. On field-grown celery, lesions usually occur on the lower, old leaves and only rarely on new developing foliage.

\section{Pathogenicity of the bacterium}

We collected celery leaves with water-soaked lesions from various locations in California, then examined 
them for bacterial streaming by sectioning tissue from lesion margins, placing sections in a drop of sterile water on a glass slide and viewing them with a light microscope. Bacteria were isolated from lesions by macerating lesion tissues in sterile distilled water and streaking the fluid onto nutrient agar, Kings' medium B for pseudomonads and a semiselective medium for Xanthomonas. Pseudomonas strains were identified to species using LOPAT tests (levan production,

Kovacs' oxidase, potato rot, arginine dihydrolase and tobacco hypersensitivity). For these biochemical and physiological tests, strains were grown on nutrient agar amended with $5 \%$ sucrose for $24 \mathrm{hr}$ before testing. The hypersensitive response was tested by infiltrating a $10^{9} \mathrm{cfu} / \mathrm{ml}$ bacterial suspension into fully expanded leaves of Nicotiana tabacum 'Havana.' Two strains of $P$. fluorescens were used as negative controls, and an American Type Culture Collection strain of $P$. syringae pv. apii (ATCC \#8722) was used as a positive control.

The ability of selected bacterial isolates to cause disease in celery was tested as follows: Isolates were inoculated into nutrient broth and grown in shake culture at room temperature for $24 \mathrm{hr}$. After shaking, Carborundum, an abrasive powder used to make minute wounds in leaf tissue, was added to the culture. Ten- to 12-wk-old celery plants were inoculated by dipping sterile cotton swabs into the culture and rubbing the swabs onto leaves that had expanded one-half to threequarters. For negative controls, plants were inoculated with nutrient broth plus Carborundum; as a positive control, the ATCC P. syringae pv. apii strain was used. We also tested selected bacterial strains isolated from diseased celery leaves, including $P$. syringae, $P$. fluorescens and a number of yellow-pigmented bacteria, for their pathogenicity on celery. Plants were maintained in a greenhouse, and 7 to 10 days after inoculation, we rated disease severity on inoculated leaves on the following scale:

$0=$ no disease reaction

$+=$ localized necrosis or chlorosis around area of inoculation

$++=$ water-soaked brown lesions developing at and around the point of inoculation

$+++=$ large expanding brown water-soaked lesions with entire area becoming necrotic

Isolations were made from inoculated leaves as described earlier.

\section{Disease incidence}

To determine the extent of the disease in production fields, we evaluated three mature celery fields in the Salinas Valley in November 1989 for disease incidence and distribution. All three fields had been transplanted with celery grown in greenhouse facilities. A computer program, Field
Runner, generated a stratified random sampling pattern based on field dimensions and plant spacing. Field Runner divided each field into uniform sectors and directed the operator to appropriate sampling sites in each sector. At each site, we rated 20 plants for the presence (one or more lesion per plant) or absence (no lesions) of the disease and entered the data into the computer. Field Runner then completed statistical analyses to determine incidence and distribution. We also collected leaf samples from selected sites within each field, examined them for bacterial streaming and cultured them to detect $P$. syringae.

\section{Bacterium isolated}

Bacterial streaming was observed from tissues of all lesions examined, and a bacterium was consistently isolated on nutrient agar and Kings' medium B. On Kings' medium B, this bacterium was fluorescent; using the LOPAT biochemical and physiological tests, we identified it as $P$. syringae (table 1). The isolates induced a hypersensitive response in tobacco, which indicates a plant pathogenic strain of $P$. syringae. A number of other bacteria were occasionally isolated from lesions, but not with the frequency and consistency of the P. syringae.

Only the $P$. syringae strains were pathogenic (table 1). On inoculated celery leaves these strains induced small water-soaked spots that turned dark brown and necrotic and eventually coalesced. Bacterial streaming was observed from these lesions, and $P$. syringae was reisolated from lesion margins. Leaves inoculated with nutrient broth did not develop symptoms, whereas leaves inoculated with the ATCC P. syringae pv. apii strain developed water-soaked brown lesions that were identical to those induced by the $P$. syringae strains isolated from California celery.

The results of the Field Runner analysis suggested a high disease incidence. The three fields surveyed had mean disease incidences of $70 \%, 34 \%$ and $81 \%$ (table 2); the disease was randomly distributed in all three fields. However, in each field the symptoms were limited to the older foliage, and 
each plant generally had only one to three lesions. $P$. syringae was consistently recovered from leaves having these symptoms.

\section{Impact of northern bacterial blight}

This is the first report of a foliar bacterial disease of celery in California, and our results indicate that this new disease is northern bacterial blight, caused by $P$. syringae pv. apii. Southern bacterial blight, caused by $P$. cichorii, has been a serious disease of celery grown in Florida. But $P$. cichorii was not isolated in this study.

Northern bacterial blight is common in New York, Michigan and Canada, where it can cause widespread blighting. The disease now appears to be distributed throughout the coastal regions of California as well. Although the incidence of bacterial blight in the field may be high, we have observed that the disease becomes severe, causing large lesions or large numbers of lesions, only if sprinkler irrigation is used throughout the production period. The disease is most prevalent and severe in the greenhouses where the plants are closely spaced, watered with overhead booms at high pressures and mowed numerous times to maintain a compact growth habit. These practices create an environment that is conducive to the development and spread of bacterial blight.

The impact of bacterial blight on the celery industry is significant: It reduces the quality of transplants and increases greenhouse disease management costs. In addition, severely infected transplants may show reduced growth in the field, serve as inoculum sources for subsequent disease spread in the field and lead to increased trimming and harvesting costs.

Symptoms of bacterial blight may resemble those of the celery fungal blights that are common in California, but a number of characteristics differentiate these diseases (table 3). Individual bacterial blight lesions tend to be $1 \mathrm{~cm}(0.4$ inches) or less in diameter, very angular in shape, water-soaked at first but later turning dark brown. The lesions extend through the entire leaf profile and are therefore visible on both the upper and lower sides of a leaf; in contrast, chemical burn or
TABLE 2. Incidence and distribution of bacterial blight in three Salinas Valley celery fields,

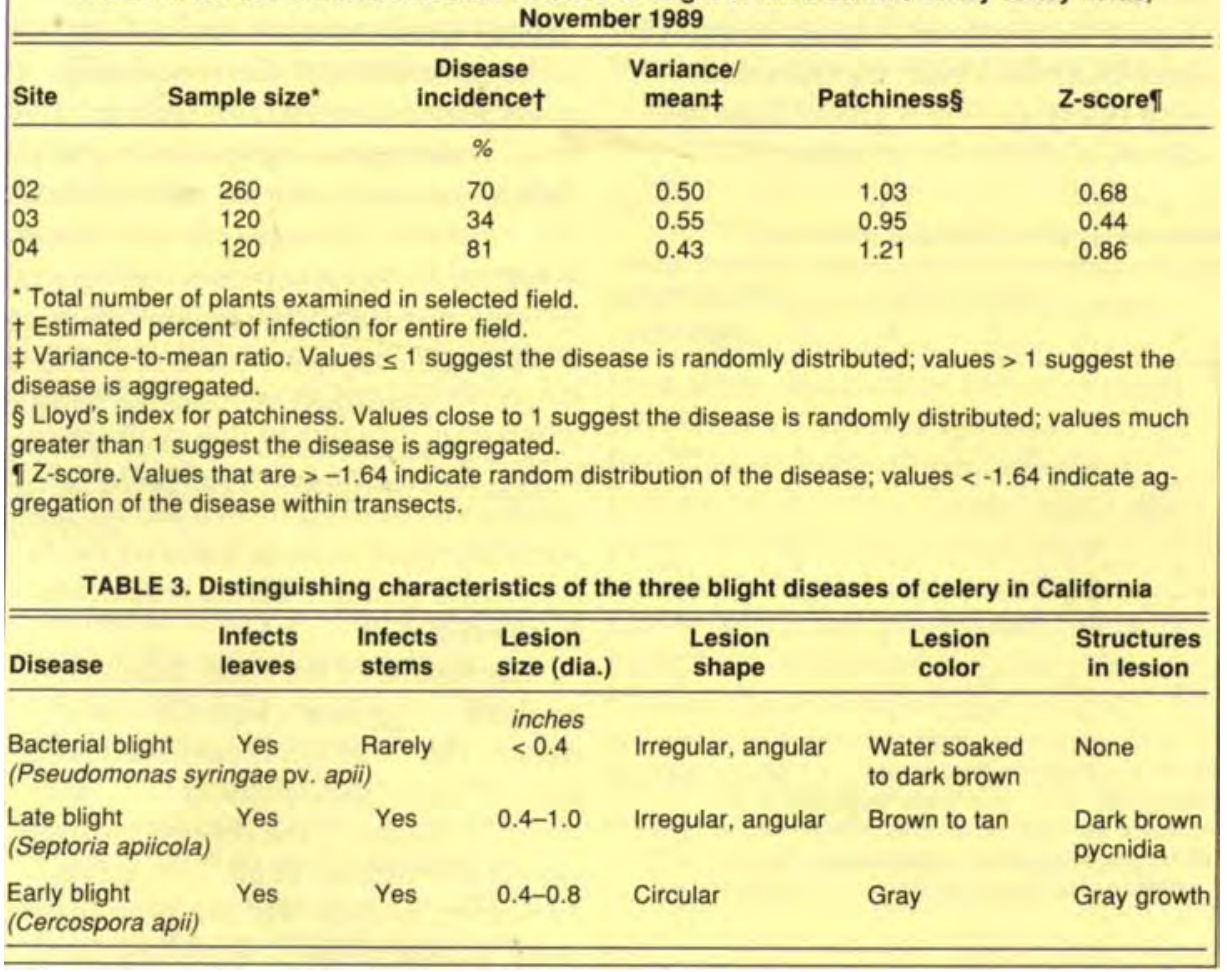

other abiotic problems tend to affect only the upper leaf surfaces. Bacterial blight lesions do not contain fungal structures and fruiting bodies, and they are generally not found on petioles.

Late blight of celery, an important disease in California caused by the fungus Septoria apiicola, differs from bacterial blight in several ways. $S$. apiicola forms profuse numbers of small, spherical fruiting bodies called pycnidia, which are scattered throughout late blight lesions and can be easily seen with a hand lens. Late blight lesions tend to be large and irregular in shape, often exceeding 2 or $3 \mathrm{~cm}$ (about 1 inch) in diameter. Further, $S$. apiicola readily infects celery petioles.

Early blight disease of celery, caused by the fungus Cercospora apii, is much less common in California. Early blight lesions are circular and gray and often are covered with the fuzzy gray growth of $C$. apii. Although early blight symptoms occur on both leaves and petioles, much like late blight, $C$. apii does not form diagnostic fruiting bodies.

Recently we have isolated $P$. syringae pv. apii from commercial celery seed lots, suggesting that the pathogen may have been introduced into California on celery seed. Future research efforts will focus on determining the level and extent of seed infestation, evaluating the efficacy of seed treatments for eradicating the pathogen from seed and defining the disease epidemiology of celery bacterial blight in California.

S. T. Koike is Plant Pathology Farm Advisor, Monterey County. E. L. Little is Graduate Research Assistant and R. $L$. Gilbertson is Assistant Professor in the Department of Plant Pathology, UC Davis. A. L. Bishop was formerly Associate Scientist, California Department of Food and Agriculture. This research was supported by the California Celery Research Advisory Board and the College of Agriculture and Environmental Sciences, UC Davis.

The authors thank C. J. Adams, A.S. Greathead, J. J. Marois and California celery transplant growers. 